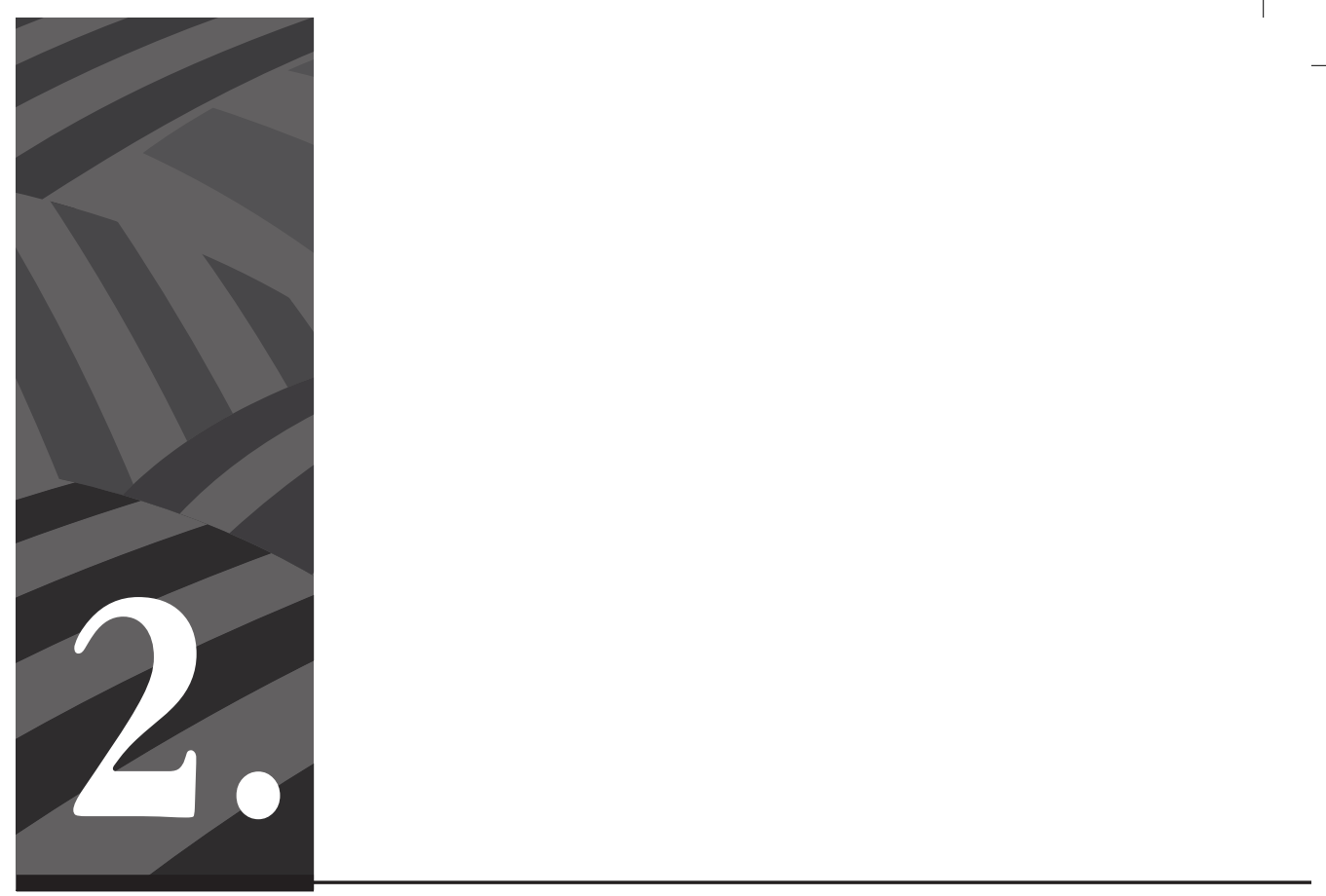

La paz como un esfuerzo social permanente desde la ciudadanía 


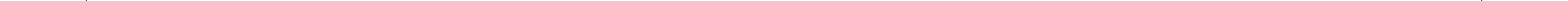




\title{
La paz como un esfuerzo social permanente desde la ciudadanía
}

\begin{abstract}
Por Daniela Márquez Torres*, María Paula Lamprea Amórtegui** y Elizabeth Molano Peña***
Resumen: La construcción de paz requiere de un compromiso y esfuerzo social constantes desde el ejercicio de la ciudadanía para superar las violencias estructurales y la cultura punitiva que las sostiene. En esta reflexión, discutimos sobre las cuestiones centrales que reproducen y normalizan la violencia en las relaciones cotidianas y hacemos una propuesta pedagógica a partir de las prácticas restaurativas, la ética del cuidado y la construcción de memoria, con el objetivo de que promuevan cambios en las formas en que nos relacionamos y asumimos nuestra corresponsabilidad desde el ejercicio de la ciudadanía.
\end{abstract}

Palabras clave: construcción de paz, ciudadanía, ética del cuidado, prácticas restaurativas, memoria.

\section{Peace: A social and permanent citizens' endeavor}

Abstract: Peacebuilding requires a constant social commitment and effort from citizens to overcome structural violence and the punitive culture that preserve them. In this reflection, we discuss about the central issues that reproduce and normalize the violence on our daily relationships and we propose a pedagogical approach based on restorative practices, ethics of care and memory construction that promote structural changes in the way we interact and assume our co-responsibility, from the exercise of citizenship.

Keywords: peacebuilding, citizenship, ethics of care, restorative practices, memory.

* Filósofa de la Pontificia Universidad Javeriana, que apoya profesionalmente en el semillero de investigación de la Fundación para la Reconciliación. Correo: daniela_marquez12@hotmail.com

** Socióloga de la Universidad del Rosario, que apoya profesionalmente en el semillero de investigación de la Fundación para la Reconciliación. Correo: mariap.amortegui@gmail.com

*** Psicóloga de la Universidad Nacional de Colombia y coordinadora del semillero de investigación de la Fundación para la Reconciliación. Correo: evaluacion@fundacionparalareconciliacion.org 
Cómo citar este artículo: Márquez Torres, Daniela; Lamprea Amórtegui, María Paula y Molano Peña, Elizabeth (2018). La paz como un esfuerzo social permanente desde la ciudadanía. Revista Controversia, 211, 63-91.

Fecha de recepción: 30 de junio de 2018

Fecha de aprobación: 20 de septiembre de 2018

\section{Introducción}

$\mathrm{E}$ n Colombia, se han naturalizado y normalizado las actitudes y acciones punitivas en lo más profundo de la cultura: la educación, la política, la economía y casi cualquier espacio que se refiera a las interacciones entre humanos. De la misma manera, el desinterés por el perdón, la corresponsabilidad de los actos y la empatía han fortalecido una cultura del castigo y el aislamiento. Si bien la justicia pretende rehabilitar a quien hace daño y mejorar su comportamiento por medio de las condenas y los castigos, lo que la sociedad ha ido aprendiendo es a minimizar las necesidades de quienes generan estos daños (victimarios o violentos), de quienes fueron afectados por ellos (víctimas) y de la sociedad misma, que aprueba esta actitud con su silencio e indiferencia.

En la cotidianidad, es común percibir roces y conflictos que surgen por la falta de diálogo y el mal manejo de emociones; sin embargo, estos problemas tienden a maximizarse en situaciones posteriores, lo que termina dividiendo a la sociedad, que cada vez se llena de más razones para actuar punitivamente con todo aquel que le genere incomodidades.

Cambiar las formas de pensar y los comportamientos de las personas que conforman esta sociedad requiere de esfuerzos y ejercicios personales, que a su vez se ratifiquen en lo colectivo. Es contradictorio desear un país en paz, si no atendemos a lo que la paz requiere y si en nuestro día a día practicamos todo lo contrario. Puede que la academia y las experiencias de otros países contribuyan a construir la pedagogía 
de paz que Colombia necesita, pero no se puede ignorar que el contexto - gracias al cual actuamos como actuamos y pensamos como pensamos - determina muchas de nuestras actitudes en torno a la paz; por esta razón, es bastante reduccionista creer que la paz es asunto de quienes han hecho la guerra.

Existen múltiples diferencias en relación con las prácticas punitivas y la paz en poblaciones alejadas del conflicto: por una parte, hay quienes se mantienen en la idea de que el Estado debe actuar con firmeza y castigar a aquellos que "obran mal"; a ellos, las garantías legales y la creencia de que "quien la hace la paga" les dan la confianza suficiente para creer que solo de esta forma se logra la paz. Por otra, algunos argumentan que, el logro de la paz y la estabilidad de un país que reconstruye lazos rotos requieren de contribuciones diarias e individuales, en las cuales se reconozca la importancia de cada persona para alcanzar un bien común.

El problema de la cultura punitiva no se sustenta en miedos personales infundamentados y vacíos, sino en un contexto y una historia que han favorecido al castigo y han silenciado el diálogo. Lo ideal (pero lo más utópico) sería fomentar una educación familiar e institucional, que resalte el consenso y la restauración; pero cambiar nuestras ideas y formas de actuar toma años de autoexamen y reflexión.

Es por esto que, en este artículo, queremos invitar a evaluar nuestras acciones cotidianas, la forma en la que reaccionamos frente a la violencia, las actitudes que tomamos con quien nos causa daño y nuestra corresponsabilidad como ciudadanos en la construcción de paz. Desde la cotidianidad y los espacios informales en los que nos relacionamos diariamente, queremos resaltar el sentido de una acción ética, que tenga como prioridad la escucha, el diálogo, la concertación de acuerdos de corresponsabilidad y la garantía de no repetición, en vez de los castigos y la exclusión. 
En ese sentido, nos fundamentamos en cuatro temas centrales, pues consideramos que estos dan origen y mantienen esa cultura punitiva: 1) la normalización de las prácticas punitivas, 2) la reproducción de esquemas punitivos desde la memoria histórica, 3) la falta de estructuras de oportunidad para generar espacios que faciliten el cambio a una cultura ética del cuidado y 4) el desconocimiento de la responsabilidad que se adquiere con la ciudadanía. A partir de la descripción de estos cuatro temas, analizaremos su sentido positivo o armónico, por medio de ejemplos y referentes teóricos que facilitan el ejercicio argumentativo.

\section{¿Cómo cambiar la cultura punitiva?}

Para proponer un cambio en aspectos tan profundos de la cultura, es necesario identificar cuáles son los puntos centrales que mantienen el sistema de creencias, valores y comportamientos. Nuestra hipótesis es que esta cultura punitiva se mantiene gracias a cuatro elementos:

1) La normalización de las prácticas punitivas en los espacios de socialización primaria: la familia, las relaciones interpersonales y el trabajo.

2) La reproducción de estructuras punitivas en espacios sociales formales: la normatividad vigente, la construcción de memoria histórica y los medios de comunicación.

3) La carencia de espacios formales e informales para generar cambios culturales permanentes.

4) El desconocimiento de la corresponsabilidad que se adquiere con la ciudadanía.

\section{La normalización de las prácticas punitivas en los espacios de socialización primaria: la familia, las relaciones interpersonales y el trabajo}

En el primer caso, es necesario recurrir a las experiencias violentas de la vida cotidiana: desde el empujón en el servicio público de transporte o la grosería del conductor al ciclista que pudo haberse atravesado en 
su camino, hasta acciones tan sutiles como el alto tono de voz en una discusión para imponer un punto de vista o la mirada de reprobación de la pareja cuando se incumple una promesa. La normalización consiste en volver habitual (cotidiano) algo que al comienzo puede ser transgresor o novedoso en un contexto determinado: una acción que inicialmente pudo parecer absurda y que ahora adquiere sentido dentro de las costumbres de un grupo o una comunidad.

La forma en que se normalizan estas prácticas punitivas tiene que ver con la manera en que tradicionalmente nos relacionamos, desde el establecimiento de jerarquías de poder hasta el uso de las palabras que usamos para dirigirnos a los demás. Ejemplos cotidianos de esto son las conversaciones familiares, en las que hablan los adultos, pero se les prohíbe a los niños opinar, el control que ejerce una persona sobre su pareja, las discusiones en el trabajo cuando hay que tomar una decisión o los medios que se usan para resolver disputas cotidianas, desde la grosería hasta las amenazas de muerte y las tentativas de homicidio.

En otros escenarios mucho más amplios, esto se manifiesta en la desigualdad social y económica, cuando a los pobres se les niega el acceso a servicios públicos o desaparecen los recursos públicos en medio de la corrupción que permea al Estado, cuando se hace uso excesivo de la fuerza en escenarios de oposición política o manifestación de descontento popular o se discrimina a las minorías o a los grupos con características especiales. Entonces, cuando ser punitivos se nos vuelve un hábito - aun cuando no haya necesidad de recurrir a la violencia física o a la transgresión de la propiedad privada-, es cuando perdemos la sensibilidad misma frente a la tragedia de la violencia y el conflicto.

Se ha vuelto recurrente escuchar sobre corrupción, estafas, robos, desplazamientos internos, amenazas a grupos sociales y líderes políticos que defienden los derechos humanos, asesinatos a líderes campesinos que intentan defender sus comunidades y tantas otras tragedias emergentes de la cultura punitiva, hasta el punto de que, incluso, se justifican 
estos hechos con discursos punitivos: "algo malo estaba haciendo para que lo amenazaran", "eso les pasa por dárselas de revolucionarios", "si hubieran estado haciendo algo productivo, eso no hubiera pasado". Estas y otras muchas otras frases demuestran la falta de empatía con aquellos que han tenido que sufrir de primera mano toda la violencia de una guerra que emergió tras la percepción de injusticia.

\section{La reproducción de estructuras punitivas en espacios sociales formales: la normatividad vigente, la construcción de memoria histórica y los medios de comunicación}

En el segundo caso, nos remitimos a la forma en que nos relacionamos en la vida diaria y a cómo estas formas son altamente influenciadas por los modelos que hemos escogido seguir: nuestros padres, abuelos, vecinos y las figuras públicas, entre otros, que aportan ideas sobre lo que es correcto o incorrecto y sobre el deber ser de nuestra relación con los demás. Nuestra posición moral y los valores que defendemos diariamente son muchas veces el reflejo de aquellos ideales y principios en los que creyeron quienes estuvieron a cargo de nuestro cuidado y protección.

A partir de acciones como saludar, despedirse, mirar o hablar, se pueden obtener muestras de la reproducción de estructuras punitivas en espacios sociales: "le negaré el saludo a Juanita, porque me cae mal", "el que no se despide, es porque no tiene decencia", "míreme a la cara cuando le estoy hablando, no me ignore" y "oiga, usted quién se cree para venir a decirme qué tengo que hacer" son expresiones comunes en la cultura colombiana, que, sutilmente, hacen un llamado a la reivindicación de valores como el respeto, la decencia, el reconocimiento o la autonomía, a través de expresiones punitivas. Si la punición se ha convertido en el deber ser de la forma en la que nos relacionarnos como sociedad, entonces estamos condenados a ser una sociedad violenta en todos los espacios de interacción social de la vida cotidiana.

Otro ejemplo, mucho menos evidente, suele darse en la construcción misma de la historia nacional. Las narrativas oficiales de lo que ha 
pasado, de lo que hemos sido y de lo que nos define como sociedad, suelen estar a cargo de quienes ostentan el poder. Y, si estas narrativas desconocen las historias del terror que muchas comunidades han tenido que sufrir, es porque, quienes ostentan este poder de narrar la historia nacional, usualmente, no desean que se conozcan dichas historias.

Lamentablemente, en el ejercicio de memoria histórica hay un grado de oficialidad que permea los relatos, lo cual reproduce escenarios autoritarios, monopoliza el sentido del pasado y reprime memorias disidentes o alternativas (Aguilar Forero, 2018). En muchos casos, el poder estatal, paraestatal o de grupos aliados, termina reduciendo la memoria a sus intereses, justificaciones y autorrepresentaciones; así, la construcción de memoria, en esos casos, queda reducida en su utilidad a beneficios políticos y económicos. De ahí la importancia de que la memoria institucional vaya acompañada de una memoria social, en la que se incluyan las versiones de todos los actores participantes.

La memoria es una construcción que reivindica una acción del pasado, para que quienes la reconocen en el presente tengan la posibilidad de aprender de los errores y reproducir aquellos aciertos. En este sentido, los líderes comunitarios, que con sus acciones de reconstrucción de memoria buscan reivindicar una lucha social o una transgresión sufrida, siguen siendo víctimas de la violencia social. Muchos de ellos, al tratar de cambiar el esquema cultural en el que vivimos, de olvido y desconocimiento, terminan siendo objeto de persecuciones políticas e incluso vuelven a ser amenazados de muerte y desaparición.

Por su parte, los espacios de la escena pública se aproximan a esta situación, en la medida en que los medios de comunicación centran sus contenidos en la exposición de los casos de injusticia y desigualdad social, para luego reclamar acciones de castigo. En esta misma línea, se encuentran las figuras políticas, que con sus discursos y sus planes de gobierno promueven proyectos de ley que afianzan dicha cultura: más años de cárcel para los ofensores, castración química para los 
violadores, inhabilidad a quienes cometan delitos dentro de su ejercicio profesional, exclusión de poblaciones especiales por miedo a que los valores tradicionales sean quebrantados o pena de muerte para corruptos o violadores de niños.

Un ejemplo de lo anterior es el nuevo plan de choque del gobierno de Iván Duque: "El que la hace la paga". Con este plan se buscó "construir seguridad con legalidad y respaldar a la Policía Nacional en la lucha contra la criminalidad" (Presidencia de Colombia, 16 de agosto del 2018), para lo cual, se han practicado múltiples acciones operacionales que han concluido con la captura de 60010 personas, a las que se les decretaron órdenes judiciales, medidas intramurales o flagrancias. Tanto en el victimario como en los castigos a impartir, el enfoque de este plan desconoce el contexto, las necesidades de las víctimas y la comunidad que reclama justicia. Asimismo, este desconoce otras formas de restauración, que puedan evitar la repetición de la agresión y garantizar el respeto a los derechos y los deberes que le corresponden al agresor.

Todo esto impone en el imaginario colectivo la percepción de que el castigo es la vía de hecho para hacer justicia y alcanzar la paz y la armonía que tanto se anhela. El desconocimiento de que estos hechos contribuyen a la generación y al aumento de la violencia en la sociedad y de que representan algunos de los problemas menos evidentes, pero más difíciles de resolver, tan solo complica más la situación: sin la consciencia de una responsabilidad compartida, no hay quién asuma el reto de cambiar la situación problemática.

\section{La carencia de espacios formales e informales para generar cambios culturales permanentes}

En el tercer caso, nos encontramos con formas en las que la cultura punitiva también ejerce sanciones a quienes intentan usar otros modos de relacionarse. Un caso muy recurrente en el día a día de los hombres colombianos tiene que ver con los desacuerdos entre ellos: cuando se presenta un conflicto entre hombres y alguno de ellos intenta usar el 
diálogo para solucionar un problema, es bastante común recibir respuestas despectivas, como "no fue capaz de pegarle", "se acobardó" o "los hombres solucionan las cosas a golpes". La violencia de género afecta predominantemente a las mujeres cuando se trata de acciones explícitas que limitan su autonomía y sus capacidades; no obstante, el hombre también es objeto de agresiones, cuando se le hacen demandas sociales sobre lo que es "ser hombre" y sobre cómo debe asumir su vida en sociedad.

Otros espacios en los que cotidianamente se castiga a quien intenta salir de estos esquemas punitivos son las comunidades ampliadas: en los colegios, cuando se castiga a quienes deberían ejercer la autoridad y se salen del marco normativo para solucionar problemas de la cotidianidad; en el vecindario, cuando se les niega el acceso a todos los cohabitantes a bienes comunes, por la transgresión a la norma que pudo haber cometido una sola persona; en el trabajo, cuando se limita el acceso a un beneficio por el mal uso que pudo haber hecho un compañero de trabajo; en las ciudades, cuando se imponen sanciones a quien está tratando de cumplir las normas, pero no les es posible controlar el comportamiento de algunas personas que no se ciñen a los acuerdos sociales ${ }^{1}$. Estos son algunos ejemplos de cómo acciones tan cotidianas asociadas al deber ser se convierten en una forma de reproducir la cultura punitiva. La norma es un acuerdo que debería facilitarnos la vida en sociedad, no entorpecerla con la fragmentación del tejido social.

1 Recientemente, el Sistema Integrado de Transporte Público de Bogotá decidió instalar unas varillas adicionales que limitan significativamente el acceso a los buses como una medida para limitar el espacio, a través del cual algunos usuarios se aprovechan del sistema y omiten hacer el pago por el uso del servicio de transporte. Esta clase de medidas se convierten en un castigo para quienes hacen buen uso del sistema, porque, en lugar de facilitar el acceso y el disfrute, fomenta el imaginario de que, si no cumples con las reglas del sistema, es necesario tomar medidas punitivas para que estas se cumplan. 


\section{El desconocimiento de la corresponsabilidad que se adquiere con la ciudadanía}

Finalmente, en el cuarto caso, es necesario remitirse a la diferencia entre la ciudadanía y la consciencia ciudadana. Una cosa es tener el derecho a la ciudadanía, que viene garantizado en muchos estados democráticos, incluido el Estado colombiano, y otra muy distinta es la consciencia de cómo ejercer dicha ciudadanía, que muchas veces viene mediada por el nivel educativo y las garantías socioeconómicas con las que se cuenta.

Aunque el estudio contribuye significativamente al desarrollo de esta consciencia ciudadana, no es una condición suficiente para su consolidación. Asimismo, es necesario tener presente cómo las desigualdades sociales, políticas y económicas afectan el ejercicio de la ciudadanía y la capacidad que se tiene para pensar, promover y trabajar por un cambio social. De este modo, entendemos la consciencia ciudadana como la capacidad de darse cuenta de que, con los derechos otorgados por la ciudadanía, también se adquieren unos deberes y una corresponsabilidad con la sociedad, y que, las acciones individuales tienen un impacto en el colectivo.

Esta capacidad de ser agente de cambio es descrita por Amartya Sen (1985) como la presencia de la intención, el significado, la motivación y el propósito que cada persona asigna a sus actividades. Esto se complementa con lo que Narayan (2005) denomina las estructuras de oportunidad, para que estas capacidades sean efectivas en el contexto de referencia de los individuos. Si bien el agenciamiento es una habilidad con el potencial de cambiar la forma de actuar de un individuo, ciertamente no es un rasgo que se manifieste de forma general en todas las actividades de cada persona. En razón a lo anterior, el agenciamiento se describe como una habilidad multidimensional, que se expresa en diferentes formas, según los dominios y estructuras de oportunidad que afecten al individuo. 
Con esta diferencia aclarada, se puede ahora comprender y evidenciar cómo muchas personas tienen dificultades para asumir esa consciencia ciudadana, especialmente, cuando se refiere a la aprehensión de su papel en la reproducción de la cultura punitiva. Muchos afirman categóricamente que no les es posible hacer nada desde su papel como ciudadanos, pues es un deber de las instituciones (y no de los ciudadanos) promover la paz en los espacios formales de la sociedad. Esto es evidente cuando alguien ve una agresión y evita involucrarse, cuando se presencia un crimen y no se denuncia o cuando se ejercen conductas cuestionables y se justifican con frases como "para qué da papaya", "era él o era yo", "el vivo vive del bobo", "si los otros lo hacen, por qué yo no puedo" o "no estoy matando a nadie". Estas son algunas de las formas con las que se apela a un sentido del deber ser (la moral), que entra en conflicto con los potenciales beneficios o riesgos (el sentido utilitarista) que puedan representar para los ciudadanos.

Estos ejemplos dan cuenta de la baja comprensión que existe de la norma como acuerdo social, que todos nos comprometemos a respetar, y de que, cuando esta se incumple, todos estamos llamados a buscar una solución que permita que la sociedad continúe existiendo después de la transgresión (bajo el supuesto de que queremos seguir viviendo en sociedad). El problema se agudiza cuando la norma se convierte en una herramienta utilitarista, que se usa cuando es conveniente para el individuo, pero que puede ser omitida cuando se aplica a este.

En consecuencia, es difícil pensar que la superación de la violencia y la consecución de la paz sucederán con la firma de un acuerdo por parte de quienes son considerados como violentos. Especialmente, porque la sociedad que espera acoger a todos aquellos que han sido excluidos voluntaria o involuntariamente de la vida civilizada — los mismos que se quejan de la violencia cotidiana y que no se han mirado internamente- no ha hecho un ejercicio reflexivo de cómo ella misma contribuye a reproducir esa cultura de la punición y no piensa qué puede hacer para cambiar estos esquemas de relación punitivos por otros más restaurativos. 


\section{Una propuesta pedagógica que promueve el cambio cultural}

Sería bastante pretencioso creer que solo con trabajos pedagógicos se puede cambiar la cultura punitiva en la que estamos inmersos; por esto, los cambios que facilitan espacios de intercambio social para discutir y proponer alternativas de solución se dan a través de las acciones cotidianas más espontáneas y normalizadas. No obstante, es necesario que, desde la cotidianidad misma en la que vivimos y en nuestro ejercicio ciudadano y profesional, empecemos a ser conscientes de la responsabilidad que implica ser parte de la sociedad y de nuestro papel en la construcción de una cultura menos punitiva, más ética y más restaurativa. $\mathrm{Al}$ asumir este reto, proponemos cuatro formas, a partir de las cuales, creemos que es posible iniciar este ejercicio de corresponsabilidad y contribuir desde nuestra particularidad en las urbes colombianas a que la paz sea un proceso permanente de construcción y transformación de las formas de relacionarnos éticamente.

\section{La forma en que nos relacionamos como una práctica cultural fundamentada en la ética y en la restauración cotidiana}

Pensar que el objetivo de la paz es la ausencia de conflicto es desconocer la naturaleza misma de la vida. El conflicto es inherente al surgimiento y desarrollo de la vida y, como tal, hay que darle su lugar en las relaciones humanas. Precisamente, escuelas de tinte biológico y psicosocial creen que el conflicto es inevitable, pues "es de la naturaleza humana y se potencializa en la dificultad de satisfacer las necesidades humanas en medio de procesos institucionales" (Osorio, 2012, p. 64). Sin embargo, la violencia sí es evitable, ya que los conflictos pueden tener una tramitación pacífica, lo que implica una dimensión ética, en la que se reconoce al otro como un otro distinto a mí.

En el conflicto hay un enfrentamiento, porque los fines de algunas de las partes se ven amenazados, pero el fin se mantiene y no se elimina. Cuando sucede la eliminación del fin, es cuando alguna de las partes 
hace un uso excesivo de la violencia para conseguir su propio fin. Cuando el conflicto escala a una tramitación violenta, es cuando se llega a la agresión. Por esto, la intención de construir paz no debería asumirse únicamente como un trabajo sobre el conflicto o la violencia, sino sobre las relaciones en las que emergen, pues, independientemente de si el conflicto tiene solución objetiva, en la forma de relacionarnos es que se evidencian los efectos más importantes del conflicto o de la paz. Para Zuleta (1992), "una sociedad mejor es una sociedad capaz de tener mejores conflictos, de contenerlos y conocerlos, de vivir no a pesar de ellos, sino productiva e inteligentemente en ellos" (Osorio, 2012).

Si establecemos las relaciones, y no los objetos o las razones, como el centro de la construcción de paz y cuando reconocemos las necesidades, la diversidad, las capacidades y las limitaciones de los ciudadanos que contribuyen a esta construcción, abrimos la posibilidad de crear espacios para que la restauración sea una práctica cotidiana que contemple las relaciones cercanas y aquellas que también construimos. Si el objetivo es mantener y fortalecer el tejido social en el momento en que se presenta un conflicto, debemos hacer énfasis en prácticas como la escucha, el diálogo, la generación de acuerdos de corresponsabilidad y la búsqueda de garantías de no repetición. En consecuencia, se deben evitar las transgresiones a la norma, la búsqueda de culpables, el ejercicio de castigos, la cuantificación de pérdidas materiales y otros tantos efectos materiales que, aunque son importantes para que la sociedad continúe existiendo, no son el factor principal en la garantía de esa continuidad.

Es por esto que la justicia restaurativa surge como una aliada de la reconciliación, el bienestar y la convivencia. Tal como afirma Ted Wachtel (2006), en su conferencia Justicia restaurativa en la vida cotidiana: más allá del ritual formal, el concepto de justicia restaurativa ha sido reservado para programas específicos de reintegración de victimarios y rituales formales de mediación entre las partes, círculos de paz o reuniones restaurativas. En ese sentido, la justicia restaurativa es una alternativa 
a la justicia retributiva o tradicional ${ }^{2}$ y una formalización de la justicia transicional $^{3}$. Para De la Rosa, Ramírez y Valencia (2018), esto se debe a que contempla la participación de todos los actores implicados para la solución de un conflicto, lo que garantiza el fortalecimiento de las comunidades, a través de la atención a las necesidades y el reconocimiento de las responsabilidades de cada actor implicado.

Como vemos, la justicia restaurativa es novedosa y le apuesta a la reconstrucción de lazos cortados por los conflictos. Sin embargo, Wachtel (2006) agrega que

a pesar de apoyar las reuniones restaurativas [herramienta formal], sería crédulo de mi parte pensar que un solo tipo de intervención restaurativa puede cambiar el comportamiento y el pensar de delincuentes y de jóvenes de alto riesgo que participan en los programas de terapia, educación y residenciales de nuestra agencia (p. 52).

Por lo anterior, Wachtel expone su punto de vista desde un contexto en particular, en el cual se enseña a los jóvenes, padres y maestros, a ser restaurativos. Aquí menciona la importancia de salirnos del marco jurídico y de pensarnos la justicia restaurativa desde las prácticas cotidianas, las cuales van más allá de una teoría o un modelo, e invita a verla como una filosofía, una forma de relacionarse con los demás, e incluso un estilo de vida en el que se cree un ambiente restaurativo a partir del uso en la cotidianidad de tales prácticas. En este sentido, nosotras nos acogemos a esta postura, en la cual, la práctica restaurativa es más importante que la justicia restaurativa, porque crea el espacio de oportunidad desde la base de la sociedad, que inevitablemente deriva en una forma de justicia formal, que piensa la resolución de conflictos

2 La justicia retributiva es aquella que se enfoca en el daño, en la cual el ofensor asume la responsabilidad de sus actos, gracias al castigo.

3 Es la aplicación a determinadas circunstancias de una política basada en los derechos humanos (ICTJ, SF). 
desde la restauración. A continuación, exponemos tres situaciones que sirven para ilustrar y complementar nuestra postura.

La forma en que se jerarquizan y se desarrollan las relaciones dentro de las instituciones educativas, en donde se suele hacer énfasis en la corrección de conductas que infringen la norma mediante el castigo, es un claro ejemplo de la cultura punitiva. Supongamos que Victoria es una estudiante de noveno grado, a quien le gusta pintarse las uñas. Un día la coordinadora de disciplina pasó revisando el porte correcto del uniforme, tal y como está escrito en el manual de convivencia, y al ver a Victoria decidió aplicar el correctivo normativo: la sacó de clases, le exigió quitarse el esmalte con lo que tuviera a la mano y, hasta que no lo hiciera, le impidió volver a clase.

Las consecuencias de la aplicación imparcial de la norma son perjudiciales para Victoria, pues no pudo compartir con sus amigas durante el almuerzo, perdió la posibilidad de asistir a sus clases y no pudo asumir sus responsabilidades escolares. Este ejemplo es una situación común en las instituciones educativas del país, en donde muchos creen que el problema se presenta cuando los niños y niñas no entienden ni cumplen las normas, pero no se reflexiona sobre las prácticas punitivas que se están reproduciendo y normalizando a través de la misma norma, que debería garantizar una convivencia pacífica.

No obstante, estas situaciones pueden recibir un tratamiento diferente. Es decir, en vez de aplicar acciones violentas como la negación del espacio para compartir con sus amigas, la limitación del acceso a sus clases y el impedimento de cumplir con sus responsabilidades, se hubiera podido dialogar con la estudiante, generar una reflexión sobre el sentido de la norma, reconocer la perspectiva de ambas (la coordinadora como quien garantiza el cumplimiento de la norma y la estudiante como aquella que debe someterse a su cumplimiento) y llegar a un acuerdo sobre lo que podría hacerse para mantener y fortalecer el sentido de comunidad en el colegio. 
A partir de una perspectiva más amplia, encontramos la segunda situación en el contexto actual colombiano, en el marco del proceso de paz con las Fuerzas Armadas Revolucionarias de Colombia (FARC-EP). Aquí, si bien existen penas carcelarias para excombatientes, también existen otras medidas que contribuyen al bienestar de las comunidades, todo esto atravesado por el esclarecimiento de los hechos violentos durante los años de enfrentamiento. Dichas medidas se enfocan en la reparación de daños específicos, como en el caso de los procesos en relación con las minas antipersonales, en los que algunos exguerrilleros, luego de recibir capacitaciones, regresan al campo para desminar senderos y trochas de distintas regiones del país (Presidencia de la República, 28 de octubre de 2016).

Las prácticas restaurativas se ejercen cuando, en lugar de simplemente juzgar al violento o al infractor por sus actos, imponer castigos y generar exclusión, se posibilitan espacios para entender sus motivaciones a través de preguntas como: ¿qué pasó?, ¿qué te motivó a hacer esto?, ¿crees que alguien salió afectado a partir de tus actos?, ¿cómo crees que nos afectó?, ¿crees que podemos acordar algo para que no se repita? Con estas preguntas, el centro no es la violación a la norma o al acuerdo, sino las consecuencias que tienen sus acciones para la persona y su comunidad.

A partir de lo anterior, se brinda la oportunidad a todos (el agresor, el agredido, los implicados) de ser escuchados y de expresar sus sentimientos y pensamientos. Esto puede ocurrir sin acudir necesariamente a mediadores o a espacios formales como los círculos restaurativos. Por eso, Wachtel (2006) hace una invitación que nosotras compartimos:

Las prácticas restaurativas deben ser sistemáticas y no situacionales. No se puede tener a unas cuantas personas implementando reuniones restaurativas y todos los demás actuando de la forma que siempre lo han hecho. No se puede ser restaurativo con estudiantes, pero retributivo con los maestros. No se puede tener un policía punitivo y tribunales restaurativos (p. 60). 
De este modo, las prácticas restaurativas pueden ser consideradas como una caja de herramientas, que no solo facilitan la resolución de conflictos en la escuela, en la familia o en la comunidad, sino que también permiten prevenir e identificar los conflictos a tiempo, tomar acciones de restauración del vínculo social y minimizar las consecuencias. Esto contribuye al fortalecimiento de los lazos sociales y emocionales entre las personas y garantiza la no repetición de las ofensas o daños, la sana convivencia y la recuperación del tejido social, pues contempla a los transgresores como parte de la sociedad. En aras de adoptar dicha filosofía, se hace necesaria la cooperación, pues no existe una única forma de resolver conflictos, pero siempre se debe tener en cuenta el contexto y las tradiciones culturales que cada comunidad tiene.

\section{La promoción de estructuras restaurativas en espacios sociales formales: la memoria colectiva}

En un ambiente de desconfianza social y polarización política, debemos preguntarnos por las actitudes y decisiones que median nuestra relación con los demás y por el deber ser que sustenta nuestras acciones cotidianas y legitima estructuras punitivas formales. En este punto, debemos pensar en los retos y las oportunidades para potenciar procesos éticos de transformación.

La memoria es una de estas estructuras que reclama acogida y responsabilidad por parte de la sociedad, pues la indiferencia, la manipulación de la información y el olvido, degradan y despojan de su dignidad tanto a las personas como a los colectivos. En algún momento, la memoria histórica se presentó como el "soporte simbólico y reparador que dignifica a las víctimas y promulga en el conjunto de la sociedad civil el reconocimiento de su pasado" (Ortega y Castro, 2010, p. 82); sin embargo, en el discurso del Estado, los desplazamientos sobre memoria y reparación han convertido a la memoria histórica en la bandera para demostrar esfuerzos gubernamentales y logros políticos, que realmente desconocen la tragedia humana que cuentan. Estos procesos han terminado 
por utilizar a la memoria como un dispositivo mediático, lejano a la sociedad, instrumentalizado y útil para intereses políticos.

Las personas encargadas de narrar la historia no deben ser amnésicas ni hacer pactos de silencio, sino que deben devolver la voz y la dignidad a aquellos afectados por el pasado. De esta manera, para Ortega y Castro, el papel de la memoria colectiva toma fuerza, porque "acerca a la sociedad a las víctimas, emprende procesos de dignificación, [...] lucha contra el olvido, la impunidad y promueve los derechos de la verdad, la justicia, la reparación [y la no repetición]” (p. 84). Si uno de los sentidos de la memoria es poder restaurar los lazos rotos y la dignidad violentada, entonces es en ella que se da lugar al reconocimiento mutuo de dignidades y del cuidado del otro. Cuando la memoria da importancia al diálogo y al compromiso con el otro, radicalmente diferente, abre procesos reflexivos y de compromiso social e invita a trascender la dimensión subjetiva y pasada, para alcanzar escenarios de proyección, en los que la apropiación y comprensión del pasado sirvan para transformar el futuro.

De igual manera, como lo afirma De Roux, hay que comprender cuál es el aporte que hace la memoria a la sociedad - aunque sea un aporte limitado para algunos-, porque no es lo mismo que la verdad; cuando se asume el sentido de la verdad - con todo lo que esta conlleva-, es posible resignificar, transformar y cambiar los relatos de dolor en comprensión (Flórez, 2018). Hacer memoria y optar por construirla colectivamente invita a la responsabilidad social, en la que se unen esfuerzos de todas las partes, para que las situaciones que hicieron daño no se vuelvan a repetir.

Al respecto, Todorov (2000) señala que hay una memoria ejemplar que invita a actuar en el presente y a tomar como ejemplo el pasado, pues no hay deber más grande para las antiguas víctimas que investigar por las presentes. Sin embargo, esta labor no es exclusiva de las víctimas; al conocer el horror del pasado, todas las personas deben alzar su propia 
voz contra el horror del presente. Ahora, esto no supone una obligatoriedad a perdonar ni a promover el olvido; más bien sugiere que, en lugar de enfocarse en la búsqueda de una única verdad, las personas deben dirigirse hacia la búsqueda del bienestar.

Contraria a la memoria ejemplar, Todorov (2000) desarrolla el concepto de la memoria literal, como aquella que preserva la literalidad de lo acontecido. Precisamente, los serbios justificaron sus atentados contra los pueblos de la antigua Yugoslavia al afirmar que sus acciones eran un desquite por los sufrimientos que habían padecido en el pasado. Esto evidencia que ellos siguieron cargando el peso de guerras milenarias como aquellas sucedidas contra turcos musulmanes y las de la Segunda Guerra Mundial. En respuesta a esto, el autor propone que el pasado no puede hacer que nos desinteresemos por el presente, pues no hay que evadir las responsabilidades sobre las miserias del presente, sino que hay que conmemorar al pasado con la intención de cuestionar al presente.

Lo anterior puede resultar difícil de asumir para las personas que han acogido una cultura punitiva, porque, para el autor,

el culto a la memoria no siempre sirve a la justicia; tampoco es forzosamente favorable para la propia memoria. [...] Pero, sobre todo, no es seguro que los procesos judiciales sean útiles para la memoria ni que ofrezcan una imagen precisa y materializada del pasado (p. 48).

En últimas, el buen uso de la memoria elimina el eterno papel de víctima para convertir a las personas perjudicadas en actores activos del presente; así, alejada de los deseos de imputar culpas (lo que no sugiere dejar de investigar quién lo hizo), la memoria funciona como método restaurativo para la dignidad de los afectados del pasado y del presente.

En un contexto más cotidiano y en la relación con nosotros mismos, el reconocimiento de nuestras necesidades y la consciencia de nuestra 
dignidad, no como un valor inherente o innato, sino como el ejercicio mismo de autocuidado, nos guían hacia la práctica de la restauración. En ese sentido, cuando las personas o comunidades tienen la necesidad de contar su historia, hay dos momentos en los que surge la posibilidad de dignificar: 1) cuando estas personas manifiestan su deseo de narrar y dar a conocer sus memorias y 2) cuando la sociedad identifica que estas personas están solicitando un reconocimiento de su causa o lucha, al tiempo que llegan a un acuerdo sobre la forma en que desean narrar dichas experiencias. Entonces, no se impone una forma correcta para que aquellas personas que buscan la reivindicación cuenten sus historias, sino que se debe construir un proceso que atienda la necesidad auténtica manifestada y responda a los marcos formales de construcción de memoria social.

\section{La facilitación de espacios que promuevan cambios culturales sostenibles en la forma en que nos relacionamos}

Desde la formalidad de las instituciones sociales y hasta en las iniciativas más informales de las organizaciones civiles se han hecho esfuerzos por generar cambios culturales en las formas de relacionarnos. Infortunadamente, muchos de estos proyectos son una instrumentalización del cambio cultural para obtener beneficios particulares, es decir, se usan como medio para obtener recursos, reconocimiento, acceso a otros espacios y se desfigura el sentido mismo de contribuir al cambio cultural. Esto no quiere decir que no haya experiencias auténticas que promuevan una cultura restaurativa, sino que, para que haya sostenibilidad en estas acciones, es necesario tener una motivación profundamente arraigada en el sistema de valores y creencias de la sociedad.

Un ejemplo de la tradición restaurativa en tribus ancestrales es el caso de la comunidad maorí, en Nueva Zelanda. Jim Consedine (2002) expone dicha tradición, a través de entrevistas a líderes de esta comunidad: "la justicia Marae es establecida para cubrir las necesidades de las víctimas. No existe para apabullar al ofensor en el barro. Tiene que ver 
con el reconocimiento de quien fue lastimado". En este sentido, el objetivo del sistema marae es "la sanación para todos; [este] proceso busca principalmente escuchar y ayudar a la víctima, sanear a la whanau ${ }^{4}$ ayudar a sanar al victimario" (p.126). Ahora, para llevar a cabo esta práctica, las familias de las personas implicadas se reúnen a discutir el problema, conocer las versiones del ofendido y del ofensor y finalmente llegar a un acuerdo.

La whanau de ambas partes en un pleito eran invitados a una huis. Era necesario que el acusado declarara su culpabilidad y no escondiera lo que había hecho. Dependía de la whanau llegar a la raíz del asunto antes de que comenzara el juicio y obtener una declaración de culpabilidad si correspondía [...]. Luego, se realizaban consultas entre las partes para determinar una forma apropiada de resolver el asunto con miras a sanear las heridas dejadas por la ofensa y restaurar las cosas a un estado 'normal' otra vez (p. 127).

Para Nueva Zelanda, la tradición maorí fue fundamental en el establecimiento de una política estatal, lo que hoy llamamos justicia restaurativa. En síntesis, lo que se busca es sanar y restaurar una ruptura a través de un proceso comunitario, que tiene por objetivo asegurar la integridad del tejido social. Para restaurar el vínculo fracturado, es necesario llegar a un consenso que garantice la sanación del $m a n a^{6}$ del ofendido, del ofensor, de las familias y del grupo social, y que este consenso "restaure el futuro orden social de la comunidad más amplia” (p. 134), es decir, que existan garantías de no repetición y se repare a la comunidad.

Como mencionamos anteriormente, a partir de tradiciones aborígenes como la maorí nace la justicia restaurativa; pero, aquí queremos resaltar la tradición más allá de la norma. Consideramos que no es necesario establecer reglas formales para aprender a convivir en comunidad, sino que, a través

\footnotetext{
4 Familia extensa (comunidad).

5 Reunión, asamblea.

6 Prestigio, estatus, poder espiritual.
} 
del reconocimiento de las demás personas, podemos entablar relaciones más horizontales: gracias a la contemplación de las necesidades de nosotros como individuos, pero también de las necesidades de las personas que nos rodean. Así, entendemos que las prácticas restaurativas están entrelazadas con la ética del cuidado, las cuales difícilmente se pueden pensar la una sin la otra.

Cuando se conciben las relaciones humanas desde una postura ética, se está pensando en el otro, en el reconocimiento de sus necesidades, en los límites y en la posibilidad de brindar el apoyo necesario. Emerge, entonces, un aspecto central para la sostenibilidad de acciones encaminadas a un cambio cultural, pues las relaciones se fundamentan en aspectos éticos de interacción y cuidado mutuo, van mucho más allá de la normatividad que formalmente las regula. La idea de que la paz es responsabilidad de los violentos o que ayudar a los pobres limita su capacidad de salir de su condición de vulnerabilidad muchas veces se fundamenta en un sentido normativo del deber ser, que reproduce la cultura punitiva y dificulta la sostenibilidad de acciones auténticas de cambio cultural. Una acción ética que se centra en el fortalecimiento del vínculo social aboga por asumir la corresponsabilidad de los integrantes de la sociedad para construir paz y configura espacios para que, sin limitar el potencial para desarrollar autonomía y autodeterminación, se superen las condiciones de violencia social estructural.

En casos en los que hay intentos de generar alternativas para la solución de conflictos y se castiga por salirse del marco normativo, se proponen acciones éticas, que rompan el ciclo de violencia que reproduce la cultura punitiva. Esto requiere de ejercicios reflexivos permanentes sobre las prácticas de justicia y cuidado, que se imparten desde la cotidianidad: el enfoque estaría en la acción ética y no en la acción moral.

Una muestra de los anterior se presenta en la familia, cuando la solución de conflictos se suele dar mediante la agresión física, verbal y psicológica. Desde prácticas éticas de la justicia y el cuidado, las acciones estarían encaminadas al reconocimiento de la afectación en el vínculo 
familiar y en cómo podría restaurarse la relación, más allá de identificar un culpable y ejercer un castigo. Al ser la familia el espacio de socialización primario, representa también una oportunidad para fortalecer la noción de que la vida nace y se mantiene en relación. No obstante, dicha oportunidad no se debe limitar a los espacios más íntimos de las interacciones sociales, también se puede remitir más ampliamente al marco de Justicia Especial para la Paz, que plantea el acuerdo de paz y las actividades delegadas a la Comisión para el Esclarecimiento de la Verdad. De esta manera, las personas implicadas podrían relatar los hechos y generar una reflexión nacional sobre lo sucedido durante la guerra y el reconocimiento que esto implica para las víctimas, puesto que valida su experiencia y pone a la verdad como un derecho y bien público necesario para la democracia ${ }^{7}$.

Entonces, en palabras de Noddings, la ética del cuidado es una ética relacional: todos nosotros iniciamos la vida en relación, y es dentro de una relación que somos reconocidos como individuos (Gómez y Martínez, 2016). La ética del cuidado está presente cuando hay reconocimiento del otro y de sus necesidades auténticas y cuando se facilitan espacios de encuentro entre las personas para compartir sus reflexiones y para ser escuchadas. En estos espacios, se reconoce el valor intrínseco de las personas, la importancia dentro de su comunidad y sus aportes para el fortalecimiento de las relaciones. Es aquí cuando se genera sostenibilidad en las prácticas culturales y en la dignificación de la relación con el otro.

\section{El desarrollo de una consciencia ciudadana y la corresponsabilidad en la construcción de un cambio cultural}

En su tesis doctoral, titulada La ética del cuidado como educación para la paz, Irene Comins describe tres elementos que deberían componer

7 La Comisión considera la verdad como un derecho de los y las colombianas, y como un bien público necesario para que se profundice la democracia y el buen vivir de esta y las próximas generaciones, por lo que buscará una verdad histórica y humana (CEV, 2018). 
el diseño curricular de una educación para la paz: lo multifactorial, la empatía y la ciudadanía. Si bien ella está pensando en un modelo complejo para abarcar los problemas que más nos afectan en la sociedad, también podemos pensar estos tres aspectos en el ámbito específico de la ciudadanía, pues es allí que interactuamos mayoritariamente con el resto de la población.

De este modo, la ciudadanía debería abarcar tres valores fundamentales para poder reconocer la responsabilidad que debe asumir. Primero, el aspecto multifactorial se entiende como la valoración y el reconocimiento de la diversidad y, con ello, de la necesidad de una capacidad crítica, que comprenda la complejidad misma de las interacciones sociales y promueva el derecho a los pueblos y a los individuos a tener dignidad. De esta manera, el acuerdo social al que llega la ciudadanía - bajo el cual todas nuestras acciones se fundamentan- contempla lo multifactorial, ya que, sin el reconocimiento de la diversidad de los seres humanos, es imposible desligarse de una cultura agresiva y punitiva ${ }^{8}$.

Segundo, para Comins (2003), la empatía o "el estado afectivo que brota de la aprehensión del estado emocional del otro y que es congruente con él” (p. 280) es necesaria para el ejercicio de la ciudadanía, en la medida en que va más allá de lo evidente e intenta comprender lo que siente la otra persona. Con esta capacidad de conexión en la que "todo nos afecta y todo puede ser afectado por nosotros" (p. 281), el ciudadano se moviliza teniendo en cuenta la historia y el contexto de la otra persona y no solo el suceso que generó el conflicto. Entonces, en lugar de continuar con la cadena de violencia que pretende castigar a todo aquel que comete algo "indeseado", la empatía busca preguntar el por qué y el para qué de sus acciones.

8 Muchos conflictos bélicos han emergido bajo la consigna de que es necesario acabar con aquellos grupos sociales que difieren en ideales y formas de relacionarse en comunidad: desde las guerras, en el Antiguo Imperio Romano, las conquistas de los pueblos amerindios y los movimientos nacionalistas de comienzos del siglo XX, hasta las batallas religiosas, políticas y militares internas en muchos países por un modelo económico y social en conflicto (Shinoda, 2018). 
Tercero, y último, Comins (2003) afirma que la ciudadanía es una práctica necesaria para el ejercicio de la democracia, además de ser el pilar fundamental de la construcción de paz. El ciudadano debe darse cuenta del valor que tiene, pues, al ser protagonista de la vida política y moral, es el que puede transformar los conceptos éticos sobre los que se ejerce la ciudadanía. Precisamente, Adela Cortina (1997) manifiesta que el ser ciudadano no se aprende por ley o por castigo, sino por degustación; por esto, no se trata de seguir a ciegas unas normas o valores impuestos que continúan estáticos con los años y que nunca se han replanteado, sino de utilizar la creatividad para apostar por los valores que creamos pertinentes para acondicionar el mundo y para que podamos vivir en él plenamente como personas ${ }^{9}$.

\section{Conclusiones}

La cultura punitiva posee marcos formales e informales que la sostienen e incluso la reivindican como una forma de construir paz. Sin embargo, es evidente que en medio de esta cultura las acciones en pro de la paz difícilmente se mantendrán en el tiempo. Mientras la esencia de la ciudadanía se centre en reproducir y normalizar la cultura de la punición, en fortalecer y mantener relaciones violentas en la sociedad y en delegar la responsabilidad de esta construcción a las instituciones formales, seremos incapaces de reconocer la humanidad misma que implica la construcción de paz.

En razón a lo anterior, nuestra propuesta se fundamenta en lograr un cambio desde lo individual y lo cotidiano, para así ir aportando al cambio cultural, lo que incluye etapas de reconocimiento, participación, responsabilidad, acción y reflexión. Como vimos, no se trata de renegar de la

9 En el libro Ciudadanos del mundo, Adela Cortina plantea que los valores nucleares e indispensables para la ciudadanía son la libertad, la igualdad, la solidaridad, el respeto activo y el diálogo o la disposición de resolver los problemas mediante el diálogo. Todos estos hacen parte del proyecto de humanidad que se ha ido construyendo, considerado como uno de los mejores para hacer al mundo más habitable y ético. 
violencia que nos rodea y optar por un rol pasivo frente a la paz, sino de asumir nuestra responsabilidad como ciudadanos, para mejorar la convivencia y generar mayor bienestar. Si bien la transformación de la cultura no será repentina y los cambios en la forma en que nos relacionamos serán notados a corto plazo, el reconocimiento y la aceptación de que estamos inmiscuidos en un ambiente de egoísmo, desconfianza y castigo representan un primer paso en la reflexión acerca de nuestras actitudes cotidianas. De igual manera, es necesario pensar en los espacios formales -y muchas veces institucionalizados-, que requieren de ese cambio cultural. Por ejemplo, la escuela, el trabajo, la universidad, las entidades del Gobierno, entre otros, son espacios que deben ser examinados para poder reconocer las normas y prácticas que impiden las buenas relaciones.

Tal y como está la situación de nuestro país, en el que la paz tambalea, queremos invitar a seguir construyendo paz desde las microesferas, porque la sumatoria de las acciones cotidianas individuales contribuye al fortalecimiento de las comunidades; así, estas acciones funcionan como una red que facilita espacios para la resolución pacífica de conflictos y reproduce estructuras restaurativas para el buen vivir. De igual forma, en el ejercicio mismo de la ciudadanía se le debe prestar especial atención a las necesidades de las otras personas, a su contexto y a su historia.

La ética del cuidado es una herramienta que faculta el cumplimiento de tal cometido, pues invita a las personas a entablar relaciones bidireccionales, en las que todos cuidamos, pero también recibimos cuidado, sin desconocer los límites que esto implica. La ética del cuidado, contraria a la ética de la justicia que entiende a todos los individuos como iguales, respeta la diversidad y busca satisfacer las necesidades del otro, para así no dañarlo ni reducirlo. Cuando nos interesamos por la singularidad de cada persona, fomentamos la sensibilidad y la empatía social, así, "las necesidades de quien requiere el cuidado se comunican y se atienden a través de interacciones sociales que pretenden un carácter horizontal y no de poder opresivo entre ambas partes" (Gómez y Martínez, 2016). 
En suma, se puede lograr integrar a la sociedad en el marco de la terminación del conflicto en Colombia, pues las responsabilidades que dejó la guerra no quedan tan solo en manos de las víctimas y los victimarios, sino que todos debemos asumir un rol fundamental para reconstruirnos como país. Es posible que aún surjan varios interrogantes respecto a las metodologías o acciones concretas que deben llevarse a cabo para que lo expuesto aquí sea posible; sin embargo, también pretendemos fomentar una autodeterminación cívica que sea capaz de interrogar a cada individuo de la sociedad. Es decir, no habría que esperar a que nos expongan una norma o a que nos den una instrucción para comenzar a examinar nuestras actitudes, sino que, a partir de nuestro propio sentido de humanidad, debemos ser capaces de distinguir aquello que aporta a la convivencia de lo que no.

\section{Referencias}

Aguilar Forero, Nicolás (2018). Políticas de la memoria en Colombia: iniciativas, tensiones y experiencias (2005-2016). Revista Histórica Crítica, (68), $110-130$.

Comins, Irene (2003). La ética del cuidado como educación para la paz (Tesis de doctorado). Castellón: Universidad Jaime I.

Comisión para el Esclarecimiento de la Verdad (2018). La Comisión inicia su mandato con el primer encuentro por la verdad. Recuperado de https://bit. ly/2TxfLP6

Consedine, John (2002). La justicia restaurativa: sanando los efectos del crimen. Bogotá: Consejo Episcopal Latinoamericano (Celam).

Cortina, Adela (1997). Ciudadanos del mundo: hacia una teoría de la ciudadanía. Madrid: Alianza.

El Espectador (4 de noviembre 2018). Distrito instala nuevos torniquetes para prevenir colados en buses del sitP de Bogotá. Recuperado de https://bit. ly/2RByBns

Figueroa, Juan Guillermo y Flores, Natalia (2012). Prácticas de cuidado y modelos emergentes en las relaciones de género: la experiencia de algunos varones mexicanos. La ventana, revista de estudios de género, 4(35), 7-57. 
Flórez, Juan Manuel (12 de mayo del 2018). Es imposible construir una nación solo entre buenos. El Tiempo. Recuperado de https://bit.ly/2FkLBeh

Gómez, Carola y Martínez, Paola (2016). Desarrollos de la PCR. En Una propuesta de pedagogía del cuidado y la reconciliación. Documento inédito de la Fundación para la Reconciliación. Bogotá.

Centro Internacional para la Justicia Transicional (ICTJ, en inglés). (s. f.). ¿Qué es la Justicia Transicional? Recuperado de https://bit.ly/1az76Fz

Narayan, Deepa (2005). Measuring Empowerment: Cross Disciplinary Perspectives. Washington: World Bank.

Narayan, Deepa y Petesch, Patti (2007). Moving out of poverty. Cross-Disciplinary Perspectives on Mobility, 1. Washington D. C.: The International Bank for Reconstruction and Development/The World Bank.

Noddings, Nel (2011). Peace education: How we come to love and hate war. Londres: Cambridge University Press.

Ortega Valencia, Piedad y Castro Sánchez, Clara Patricia (2010). Rostros y rastros de una pedagogía de la memoria. Revista Nodos y Nudos, 3(28), 81-91.

Osorio García, Sergio Néstor (2012). Conflicto, violencia y paz, un acercamiento filosófico y bioético. Revista Latinoamericana de Bioética, 12(2), 52-69.

Presidencia de Colombia (2018). Presidente Duque lanza plan de choque "El que la hace la paga” por los próximos 100 días. Presidencia de la República de Colombia. Recuperado de https://bit.ly/2D4fEpe

Presidencia de la República (2016). Excombatientes aprenderán sobre desminado humanitarios en el Meta. Presidencia de la República de Colombia. Recuperado de https://bit.ly/2Qqo1i1

Ramírez, Daniela, De la Rosa Guzmán, Eilyn y Valencia, Nelson (2018). Justicia retributiva y restaurativa: Análisis comparado a través de estudios de caso en el Valle del Cauca. Revista Iberoamericana de Psicología: Ciencia y Tecnología, 11(1), 55-64.

Sen, Amartya (1985). Well-Being, Agency and Freedom: The Dewey Lectures 1984. The Journal of Philosophy, 82(4), 169-221. 
Shinoda, Hideaki (2018). Peace-building and State-building from the perspective of the historical development of international society. International Relations of the Asia-Pacific, 18(1), 25-43.

Todorov, Tzvetan (2000). Los abusos de la memoria. Buenos Aires: Paidós.

Wachtel, Ted (1999). Justicia restaurativa en la vida cotidiana: más allá del ritual formal. Documento presentado en la Conferencia Reconfigurando las Instituciones Australianas: Justicia Restaurativa y Sociedad Civil. Camberra: The Australian National University. 